\title{
Dual Bands Microstrip Substrate Integrated Waveguide (SIW) Antenna for K-band Applications
}

\author{
Rand Muwafaq Hadi ${ }^{1,2}$, Faris Mohammed Ali $^{2}$, Ghufran M. Hatem ${ }^{2}$ \\ ${ }^{I}$ Najaf Technical Institute, Al-Furat Al-Al-Awsat Technical University, Al-Najaf 31001, Iraq. \\ E-mail: rand.muaffaq@gmail.com \\ ${ }^{2}$ Communications Eng. Dept., Najaf Technical College, Al-Furat Al-Al-Awsat Technical University, Al-Najaf 31001, Iraq..
}

E-mail: ghufranmahdi@etcn.edu.iq

\begin{abstract}
A dual bands circular slot based on a substrate integrated waveguide (SIW) antenna is presented in this paper for K-band applications. The proposed antenna structure is consisting of a microstrip antenna with two circular-shape slots etched on the top of radiation plane and located one on top of the other for bandwidth enhancement. This antenna has been printed on an FR-4 substrate with a dielectric constant 4.3 of and thickness of $1.5 \mathrm{~mm}$. The optimized antenna resonates at $22.45 \mathrm{GHZ}$ and $25 \mathrm{GHZ}$ with a fractional bandwidth of $1.20 \mathrm{GHZ}$ about $(5.353 \%)$ and $1.50 \mathrm{GHZ}$ about $(5.994 \%)$, respectively. The achieved peak gain is about $6.14 \mathrm{~dB}$ and $4.72 \mathrm{~dB}$ over the operating frequencies, respectively, this makes it suitable for $\mathrm{K}$ applications with good matching and return loss characteristics. Design model and performance evaluation of a proposed antenna has been executed by EM simulator, CST Microwave Studio.
\end{abstract}

Keywords — dual bands, Microstrip, substrate integrated waveguide SIW, K-band.

\section{INTRODUCTION}

since 1980 the wireless communications rapidly developing as with the first development of the $1 \mathrm{G}$ network. To date, Wireless communications have reached a level of the $4 \mathrm{G}$ network, which it has been designed to apply the requirements of wireless standards such as LTEAdvanced requirements and IEEE 802.16m [1]. Today, wireless networks and mobile phones could be found anywhere. The speed of transfer data in modern communication has been in a tremendous demand in wireless networks. Because of that, the basic challenges for the developers in developing the future wireless system are the increasing need for higher transmission rates and the growing number of users. For example, the uncompressed high-definition video and image requirement a very high data transmission rate (more than 1Gbps) in wireless transmission.

Due to limited bandwidth, it is difficult to achieve transmission data rate like that because of the traditional wireless systems using frequencies up to $10 \mathrm{GHz}$ [2]. The higher frequencies need conventional waveguide that have very good properties in transmission, the (first generation $1 \mathrm{G})$ of the microwave transmission directorial (guiding) structures is the conventional waveguides, There were advantages of high power handling capacity and high $\mathrm{Q}$ factor, but also big that is the drawback of it.
Printed transmission lines are the next generation of microwave guiding elements it is used in Microwave Integrated Circuits (MICs). the advantages of ( MICs) is low profile structures but the disadvantage is missing the high capacity to transport power and high $\mathrm{Q}$ factor of the traditional waveguides. to overcome these issues between (MIC) structures and traditional waveguides, Substrate Integrated Circuits (SICs) developed that have the advantages of planar low profile structures such as MIC structures, even with high power carrying capacity and high $\mathrm{Q}$ factor, such as waveguides [3]. The substrate integrated waveguide (SIW) is one of the techniques of SIC. The SIW technology has been well-applied on the microwave components, include antennas, active circuits and passive components [4]. For microstrip transitions Feasibility of the concept has been proved in [5]. Coplanar waveguide transition also designed in [6][7], Simple waveguide filter and slot antennas have been presented in [8],[9],[10]. The radiation loss generated between gaps of the vias was defined in [11]. Incorporating rectangular waveguide into a microstrip of the substrate reduces the Qfactor of the waveguide because of volume reduction and dielectric filling [6]. SIW proposed good result when it used in antenna structure as we will see next. 


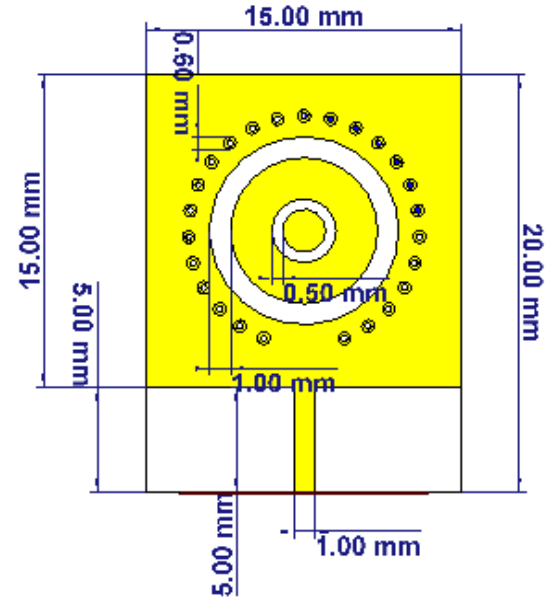

Fig. 3: The geometry of proposed SIW antenna

TABLE I: PARAMETER AND DIMENSION OF SIW ANTENNAS (IN MM).

\begin{tabular}{lll}
\hline Symbol & Value & Description \\
\hline $\mathrm{L}$ & 20 & Total length \\
\hline $\mathrm{W}$ & 15 & Total width \\
\hline $\mathrm{D}$ & 0.6 & Via diameter \\
\hline $\mathrm{P}$ & 1.2 & $\begin{array}{l}\text { Pitch between } \\
\text { vias }\end{array}$ \\
\hline Lms & 5 & $\begin{array}{l}\text { Length of } \\
\text { microstrip feed }\end{array}$ \\
\hline $\mathrm{Wms}$ & 1 & $\begin{array}{l}\text { Width of } \\
\text { microstrip feed }\end{array}$ \\
\hline $\mathrm{Lp}$ & 15 & Patch length \\
\hline $\mathrm{Wp}$ & 15 & Patch width \\
\hline $\mathrm{h}$ & 1.5 & $\begin{array}{l}\text { Thickness of } \\
\text { substrate }\end{array}$ \\
\hline $\mathrm{S} 1$ & 1 & outer slot \\
\hline $\mathrm{S} 2$ & 0.5 & Inner slot \\
\hline
\end{tabular}

\section{RESULTS AND DISCUSSION}

The first proposed antenna has designed without (SIW) as shown in Fig. (4) to calculate and compare our results. The Simulation results show that it has single band within the sweep frequency of $(18-27) \mathrm{GHz}$ with resonant frequency at about $23 \mathrm{GHz}$ as shown in Fig. (5).

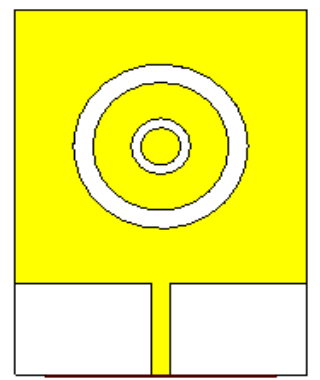

Fig. (4): The proposed antenna without SIW

The s11 parameter shown in figure below:

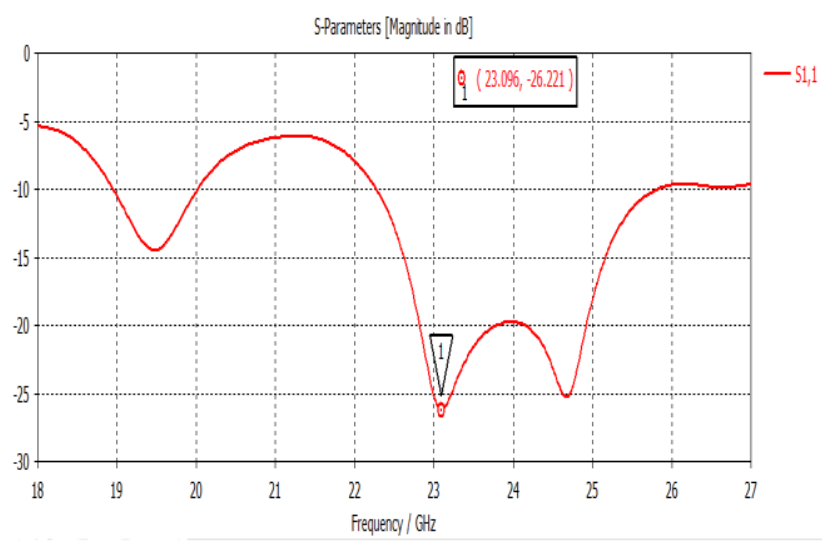

Fig. (5): s11 parameter for the proposed antenna without SIW.

The directivity and peak gain value of the single band have been calculated. In this frequency band, the directivity of the antenna is $(7.29 \mathrm{~dB})$ with the peak gain is $(3.62 \mathrm{dBi})$ and the band width is $(3.62 \mathrm{GHZ})$ the antenna has low efficiency, The CST simulation of radiation pattern plots for the horizontal plane and the vertical planes respectively, the results show that the antenna almost offers semiomnidirectional directivity. Fig. (6-a) shows the directivity in $3 \mathrm{D}$ and polar form and Fig.(6-b) shows the peak gain 3D and polar.
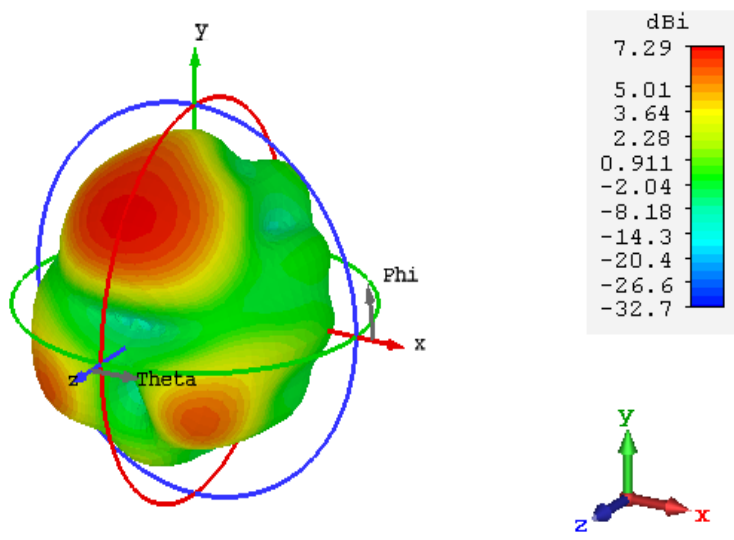

(a) at $\mathrm{F}=23 \mathrm{GHz}$ 
Al-Furat Journal of Innovation in Electronics and Computer Engineering (FJIECE) is an international, open access, interdisciplinary, quarterly, and double blind peer-reviewed journal published by Al-Furat Al-Awsat Technical University/Iraq. It is dedicated to the latest advancement in Electronic Engineering, Computer engineering, and their related and subfields.

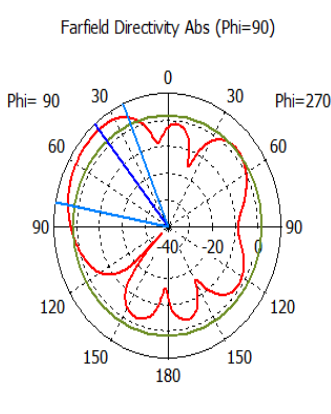

Theta / Degree vs. dBi
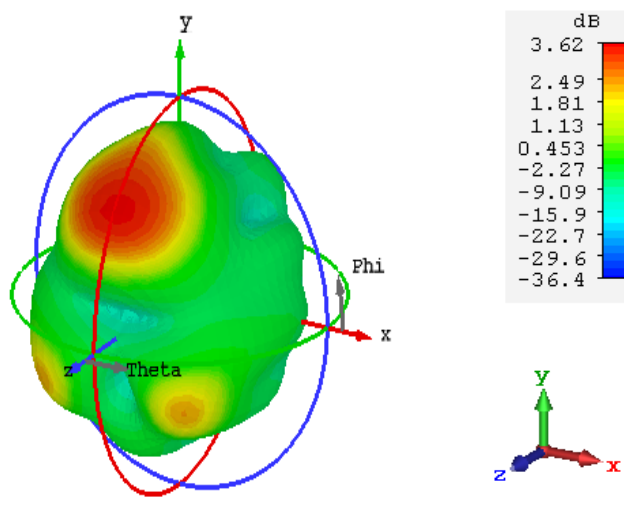

(a) at $\mathrm{F}=23 \mathrm{GHz}$

Farfield Gain Abs (Phi=90)

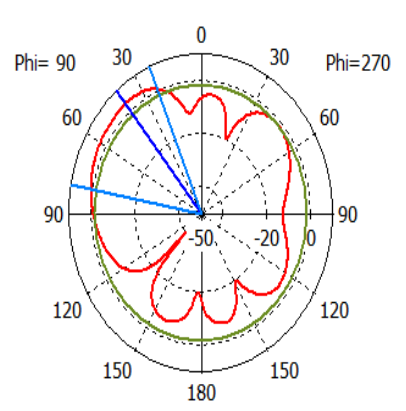

Theta / Degree vs. dB

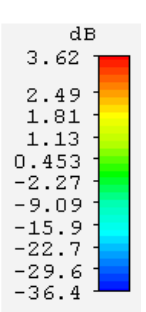

— farfield $(f=23)[1]$

Frequency $=23 \mathrm{GHz}$

Main lobe magnitude $=7.29 \mathrm{~dB}$ Main lobe direction $=40.0 \mathrm{deg}$. Angular width $(3 \mathrm{~dB})=56.6 \mathrm{deg}$

Frequency $=23 \mathrm{GHz}$

Main lobe magnitude $=3.62 \mathrm{~d}$

Main lobe direction $=40.0 \mathrm{deg}$.

Angular width $(3 \mathrm{~dB})=56.6 \mathrm{deg}$

Fig. (6): (a) The directivity (b) gain foe the proposed antenna

When SIW technology add to the antenna the result enhanced and give the required that need .The antenna with SIW shown in fig. (7).

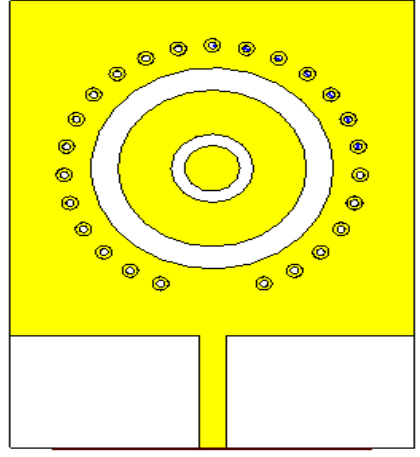

Fig. (7): Proposed antenna with SIW .

The result of S11 response has been presented in Fig. (8). The antenna has dual-band resonant behaviour at 22.45 $\mathrm{GHz}$ and $25 \mathrm{GHz}$ with bandwidth $(1.20 \mathrm{GHz})$ for the lower band, and 1.50 GHZ for the upper band for return loss $\leq$ $10 \mathrm{~dB}$ respectively. This makes the proposed SIW antenna suitable for the requirement of $5 \mathrm{G}$ mobile communication, radar and satellite systems.

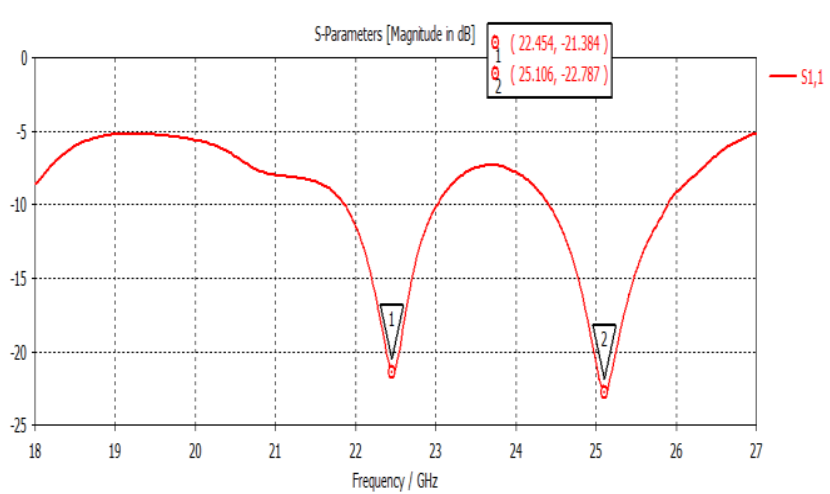

Fig. (8) : The s11 parameter of the SIW antenna

The directivity and gain of the first resonant frequency is (9.26 $\mathrm{dB}$ and $6.14 \mathrm{dBi}$ ), receptivity. As shown in fig. (9) below:
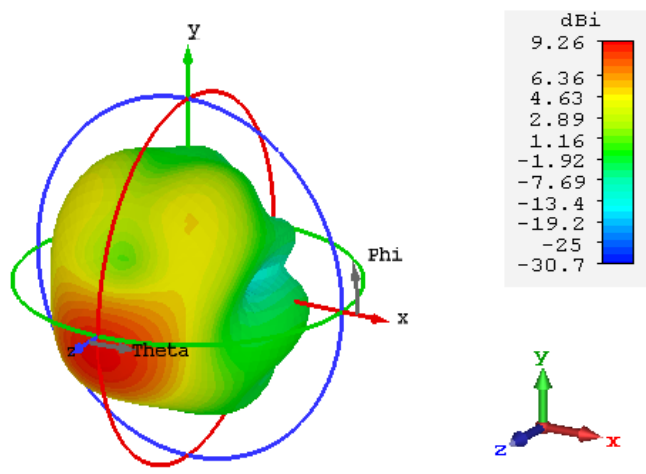

(a) $\mathrm{F}=22.45 \mathrm{GHz}$ 


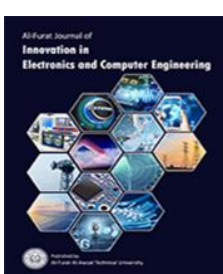

Al-Furat Journal of Innovation in Electronics and Computer Engineering (FJIECE) is an international, open access, interdisciplinary, quarterly, and double blind peer-reviewed journal published by Al-Furat Al-Awsa Technical University/Iraq. It is dedicated to the latest advancement in Electronic Engineering, Computer engineering, and their related and subfields.

Farfield Directivity Abs (Phi=90)

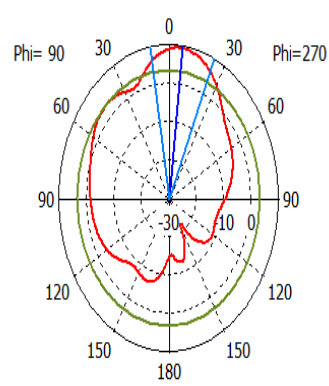

Theta / Degree vs. dBi

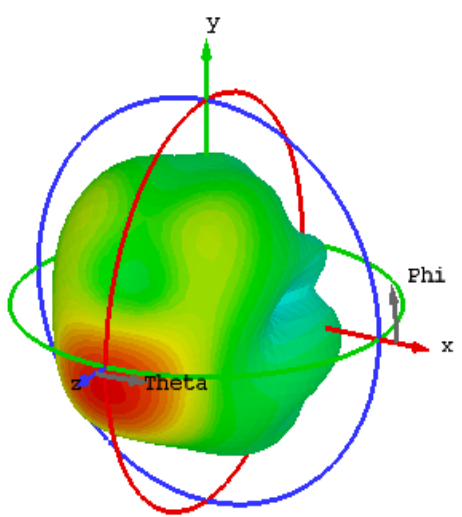

(a) $\mathrm{F}=22.45 \mathrm{GHZ}$
Frequency $=22.454 \mathrm{GHz}$ Main lobe magnitude $=9.28 \mathrm{dBi}$ Main lobe direction $=7.0 \mathrm{deg}$ Angular width $(3 \mathrm{~dB})=34.2 \mathrm{deg}$.
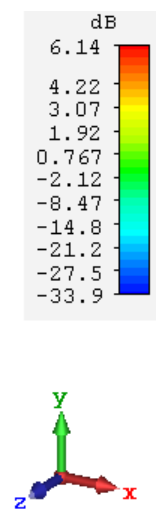

Frequency $=22.454 \mathrm{GHz}$ Main lobe magnitude $=6.16 \mathrm{~dB}$ Main lobe direction $=7.0 \mathrm{deg}$. Angular width $(3 \mathrm{~dB})=34.2 \mathrm{deg}$.
Theta / Degree vs, dB

Fig. (9): directivity and gain at $F=22.45 \mathrm{GHZ}$.

The result of the second resonant frequency (25 GHZ) the directivity is $(8.19 \mathrm{dBi})$, gain is $(4.72 \mathrm{~dB})$. The result of the directivity and gain are shown in fig. (10), below in 3D and polar form:

Farfeld Directivity Abs (Phi=90)
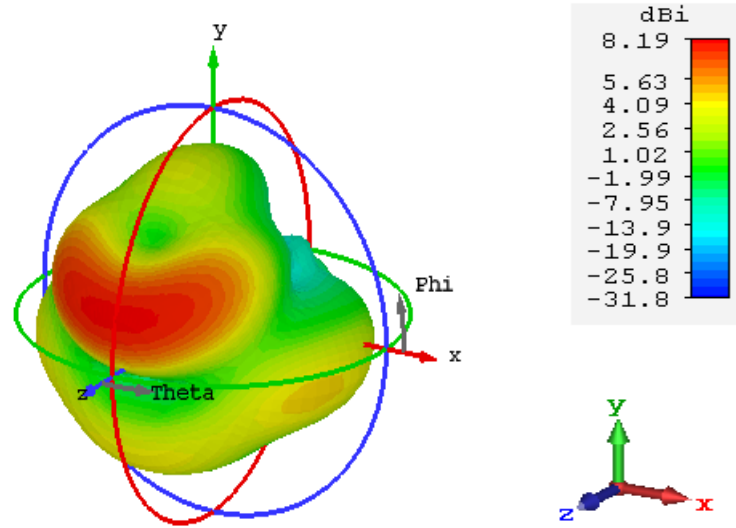

(a) $\mathrm{F}=25 \mathrm{GHz}$

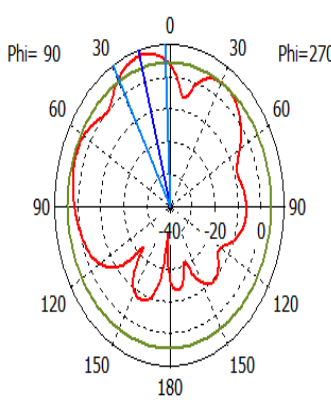

Theta / Degree vs. dBi

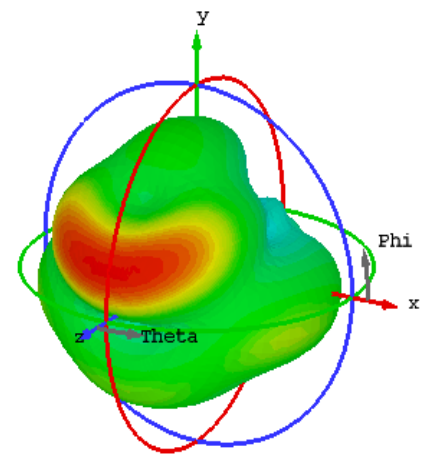

(a) $\mathrm{F}=25 \mathrm{GHZ}$
— farfield $(f=25.106)[1]$

Frequency $=25.106 \mathrm{GHz}$

Main lobe magnitude $=8.19 \mathrm{~dB}$ Main lobe direction $=16.0 \mathrm{deg}$. Angular width $(3 \mathrm{~dB})=26.9 \mathrm{deg}$.
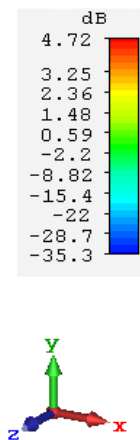
